\title{
Analysis of Coupled Multiphase Fluid Flow, Heat Transfer and Mechanical Deformation at the Yucca Mountain Drift Scale Test
}

\author{
Rutqvist, J., Tsang, C.-F., and Tsang, Y. \\ Lawrence Berkeley National Laboratory, Berkeley, California, USA
}

\begin{abstract}
A numerical simulation of coupled multiphase fluid flow, heat transfer, and mechanical deformation was carried out to study coupled thermal-hydrological-mechanical (THM) processes at the Yucca Mountain Drift Scale Test (DST) and for validation of a coupled THM numerical simulator. The ability of the numerical simulator to model relevant coupled THM processes at the DST was evaluated by comparison of numerical results to in situ measurements of temperature, water saturation, displacement, and fracture permeability. Of particular relevance for coupled THM processes are thermally induced rock-mass stress and deformations, with associated changes in fracture aperture and fractured rock permeability. Thermally induced rock-mass deformation and accompanying changes in fracture permeability were reasonably well predicted using a continuum elastic model, although some individual measurements of displacement and permeability indicate inelastic mechanical responses. It is concluded that fracture closure/opening caused by a change in thermally induced normal stress across fractures is an important mechanism for changes in intrinsic fracture permeability at the DST, whereas fracture shear dilation appears to be less significant. Observed and predicted maximum permeability changes at the DST are within one order of magnitude. These data are important for bounding model predictions of potential changes in rock-mass permeability at a future repository in Yucca Mountain.
\end{abstract}

\section{INTRODUCTION}

The Yucca Mountain Drift Scale Test (DST) is a multiyear, large-scale, underground heating test conducted by the U.S. Department of Energy at Yucca Mountain, Nevada. The DST is designed to study coupled thermal-hydrological-mechanical-chemical (THMC) processes in unsaturated fractured and welded tuff. The DST evolution has the same processes operating over a similar range of thermal conditions as that of a future Yucca Mountain repository. Therefore, DST data are used to validate 
models of those processes such that the models can be shown to be useful for modeling the post-closure behavior of the system.

Pre-test predictions of coupled thermal-hydrological (TH) and thermal-mechanical (TM) processes at the DST and validation of TH and TM models have previously been conducted as part of the Yucca Mountain site characterization project. These predictions included three-dimensional simulations of $\mathrm{TH}$ processes conducted by the Lawrence Berkeley National Laboratory using the TOUGH2 code $[1,2,3]$ and the Lawrence Livermore National Laboratory using the NUFT code [4]. Coupled TM processes have been simulated by the Sandia National Laboratories using the JAS-3D code [5] and by the Lawrence Livermore National Laboratory using the 3-DEC code [6]. However, no fully coupled THM analysis of the DST was performed until recently, when Rutqvist et al. [7, 8] applied a model for the analysis of coupled THM processes under multiphase flow conditions. This paper presents the current results of such a coupled THM analysis of the DST.

Experience from the earlier modeling studies of coupled TH and TM processes at Yucca Mountain has been very valuable for development of the coupled THM model applied in this paper. In the pre-test prediction of coupled TH processes at the DST, Birkholzer and Tsang $[1,2]$ developed a threedimensional numerical model based on previous experience in simulating the Yucca Mountain Single Heater Test (SHT) in the same formation. The modeling of the SHT had shown that an overlapping continuum model, is appropriate for modeling fracture and matrix interactions with multiphase, multicomponent fluid flow and heat transfer. As a result, an overlapping continuum model, or more specifically, a dual-permeability model (DKM), was also adopted in the pre-test prediction of coupled TH processes at the DST.

In a pre-test prediction of coupled TM processes at the DST, Francis et al. [5] applied a ubiquitously fractured continuum model also based on their previous experience in modeling the SHT. A reasonably good agreement between simulated and measured displacements in both studies confirmed the appropriateness of the continuum approach. Furthermore, a comparison between simulation results of a discrete-fracture model and a continuum model by Blair [6] showed minor differences regarding mechanical displacements. This indicates the dominance of thermo-elastic expansion of the rock matrix, although locally a small slip may occur along fracture planes.

This paper presents recent results of a numerical analysis of coupled THM processes at the DST. The analysis was conducted with TOUGH-FLAC [7], a simulator based on the coupling of two established computer codes: TOUGH2 [9], used for coupled thermal-hydrological analysis and FLAC3D [10], used for mechanical analysis. Simulated processes include heat transfer by conduction and convection, liquid and vapor water movements, rock stress and deformation, and stress-induced changes in fracture permeability. In this paper, model predictions of coupled THM responses are compared to in situ measurements of temperature, water saturation, rock-mass displacement, and changes in fracture permeability. Recent code-to-code comparison with measured data at the DST within an international code-comparison project is also briefly summarized.

\section{THE YUCCA MOUNTAIN DRIFT SCALE TEST}

The ongoing Drift Scale Test is located at Yucca Mountain, in a side alcove of an underground tunnel, the Exploratory Studies Facility (ESF), at a depth of about $250 \mathrm{~m}$ in the middle nonlithophysal zone (Tptpmn) of the Topopah Spring Tuff formation. The DST centers around a heated drift, $5 \mathrm{~m}$ in diameter and $50 \mathrm{~m}$ long (Fig. 1). Heating is provided by floor heaters along a $47.5 \mathrm{~m}$ long section of the heated drift, as well as by 50 rod heaters, referred to as "wing heaters," which are placed into horizontal boreholes emanating from, and orthogonal to, the heated drift (Fig. 1). The heaters of the DST were activated on December 3, 1997, and the heating continued for approximately four years, 
until January 14, 2002, when heater power was turned off. Currently, the DST is in the midst of a fouryear period of natural cooling.

Measurements at the DST include laboratory and field characterization of fractured and welded tuff formation surrounding the heated drift. Preheat laboratory characterization included measurements of thermal, hydrological, and mechanical properties, mineral-petrology studies, and pore-water chemical and isotopic analysis. Preheat field characterization involved rock-mass classification, fracture mapping, video logging of boreholes, geophysical measurements, and air-injection fracture permeability testing.

After activation of the heaters, scientists conducted passive monitoring and active testing during the heating phase, which is still ongoing as part of the subsequent cooling phase. The rock mass surrounding the heated drift has been instrumented with thousands of sensors to monitor the thermal, mechanical, hydrological, and chemical processes on at least an hourly basis [11].

In Fig. 1, the instrumented boreholes are color-coded according to their functions. For the purposes of studying THM processes, the focus is on boreholes designed to measure thermal (yellow), hydrological (blue), and mechanical (green) responses. Radial arrays of $20 \mathrm{~m}$ long boreholes drilled from the heated drift, and boreholes drilled parallel to the drift, are used for monitoring the temperature evolution. Temperature sensors in each borehole are installed at approximately $30 \mathrm{~cm}$ intervals. Most boreholes labeled as "hydrology" in Fig. 1 originate from the observation drift. These are clusters of $40 \mathrm{~m}$ long boreholes forming vertical fans that bracket the heated drift and the wing heaters. These boreholes are used for periodic active air-injection testing to track changes in permeability of the fracture system. Deformation of the rock mass is being monitored with an array of multiple-point borehole extensometer (MPBX) systems. In the radial MPBX boreholes, four anchors are attached to the borehole wall at a distance of about $1,2,4$, and $15 \mathrm{~m}$ from the drift wall. The displacements of each anchor relative to the drift wall are continuously monitored.

\section{MODEL CONCEPTUALIZATION OF THE DST}

The DST is simulated with TOUGH-FLAC in a two-dimensional cross section $(250 \mathrm{~m}$ high, $200 \mathrm{~m}$ wide) oriented normal to the drift axis (Fig. 2a). The highly fractured rock mass at the test site is modeled as a dual-permeability medium, which consists of interacting matrix and fracture continua [1, 2]. The dual-permeability continuum model approach has been proven suitable for modeling of fluid flow and heat transfer in the unsaturated zone at the Yucca Mountain, since it realistically captures the partitioning of simultaneous fluid flow in both the fractures and rock matrix. The continuum approach is deemed appropriate, because the rock mass in the unsaturated zone at Yucca Mountain is intensively fractured. Fracture mapping at the site shows three dominating fracture sets [12]:

1) A prominent vertical, southeast trending

2) A less prominent vertical, southwest trending

3) A less prominent subhorizontal

The average spacing for mapped fractures of length larger than $1 \mathrm{~m}$ is about 0.3 to $0.4 \mathrm{~m}$. However, detailed cell mapping has shown that about $80 \%$ of

the fractures at the site are less than one meter, and therefore the fracture spacing counting all fractures would be less than $0.3 \mathrm{~m}$. Moreover, air-permeability tests conducted in short-interval $(0.3 \mathrm{~m})$ packedoff boreholes sections show that fluid conducting fractures exist at least every $0.3 \mathrm{~m} \mathrm{[13].} \mathrm{This}$ evidence of a highly fractured rock justifies the use of a continuum modeling approach. 
For the Yucca Mountain site, incorporation of stress effects into hydraulic properties is based on a conceptual model of a highly fractured rock mass that contains three orthogonal fracture sets, as shown in Fig. 2b. Porosity correction factor $\left(F_{\phi}\right)$ and permeability correction factors $\left(F_{k x}, F_{k y}, F_{k z}\right)$ are calculated from the initial and current apertures $\left(b_{1 \mathrm{i}}, b_{2 i}, b_{3 i}\right.$ and $b_{1}, b_{2}, b_{3}$, respectively) in fracture sets 1,2 , and 3 , according to [7]:

$$
\begin{aligned}
& F_{\phi}=\frac{b_{1}+b_{2}+b_{3}}{b_{1 i}+b_{2 i}+b_{3 i}} \\
& F_{k x}=\frac{b_{2}^{3}+b_{3}^{3}}{b_{2 i}^{3}+b_{3 i}^{3}}, F_{k y}=\frac{b_{1}^{3}+b_{3}^{3}}{b_{1 i}^{3}+b_{3 i}^{3}}, F_{k c}=\frac{b_{1}^{3}+b_{2}^{3}}{b_{1 i}^{3}+b_{2 i}^{3}}
\end{aligned}
$$

where fractures in sets 1,2 , and 3 are assumed to be equally spaced and oriented normal to $x, y$, and $z$ directions, respectively, and a parallel-plate fracture flow model is adopted. The capillary pressure is corrected for porosity and permeability changes according to a Leverett [14] type of relationship:

$$
F_{P_{c}}=\sqrt{\frac{F_{k}}{F_{\phi}}}
$$

where

$$
F_{k}=\sqrt[3]{F_{k x} \times F_{k y} \times F_{k z}}
$$

In this study, the current fracture aperture $b$ depends on the current effective normal stress $\sigma_{n}^{\prime}$, according to an exponential function:

$$
b=b_{r}+b_{m}=b_{r}+b_{\max }\left[\exp \left(d \sigma_{n}^{\prime}\right)\right]
$$

where $b_{r}$ is a residual aperture, $b_{m}$ is mechanical aperture, $b_{\max }$ is the maximum mechanical aperture, and $d$ is a parameter related to the curvature of the function (Fig. 2c). Equation (5) can be inserted into Equation (2) to derive expressions for rock-mass permeability correction factors in $\mathrm{x}, \mathrm{y}$, and $\mathrm{z}$ directions.

\section{MATERIAL PROPERTIES AND INITIAL CONDITIONS}

The material properties of the DST test block are presented in Table 1. These include both matrix and fracture hydrological properties for the dual-continuum approach, as well as equivalent continuum rock-mass mechanical properties. Hydrological properties include water-retention curves and relative permeability functions based on van Genuchten's [15] model. Mechanical properties include a fractured rock-mass deformation modulus of $14.77 \mathrm{GPa}$, which is about $50 \%$ lower than Young's modulus of intact rock. A temperature-dependent thermal expansion coefficient derived based on measurements of intact core samples from the site (See also Millard and Rutqvist, [16]). The parameters $b_{\max }$ and $d$ defining the stress-aperture relationship in Equation (5) have been estimated by model calibrations against various field experiments at Yucca Mountain (described by Rutqvist and Tsang [17]). In the analysis presented here, a $b_{\max }$ of $150 \mu \mathrm{m}$ and $d$ of $0.6 \mathrm{~Pa}^{-1}$ were determined by recent calibration presented in Rutqvist 2004 [18].

The initial conditions for the simulation are presented in Table 2. At Yucca Mountain, vertical stress calculated from the weight of the overburden is the maximum principal stress, whereas the horizontal stresses are estimated to be about half the magnitude of the vertical stress. At an ambient temperature of $25^{\circ} \mathrm{C}$, the matrix is almost fully saturated with water, whereas fractures are almost dry (as a result of matrix water imbibition). 


\section{MAIN THM RESPONSES DURING THE HEATING TEST}

The coupled THM responses at the DST are driven by changes in rock temperature during the four-year heating period and the following natural cooling period. After the heaters are turned on, the temperature at the drift wall rise to the boiling point (about $96^{\circ} \mathrm{C}$ ) within three months (Fig. 3). After a short pause in the temperature rise, while liquid water in the rock matrix and reflux water in the fractures was vaporized, the temperature continues to rise at a slower rate. During the test, the thermal input was manually reduced by $10 \%$ a few times to maintain the drift-wall temperature at about $200^{\circ} \mathrm{C}$ (Fig. 3).

Fig. 4a-f present simulated results of TOUGH-FLAC after one year of heating, illustrating the main coupled THM processes at the DST. Fig. 4a shows that after one year of heating, the temperature has risen above the boiling point around the heated drift and near the wing heaters. High temperature induces evaporation of liquid matrix water and drying near the heat source (Fig. $4 \mathrm{~b}$ and c, dryout zone). Some of the evaporated water is transported as vapor away from the heat source in the permeable fracture system toward cooler regions, where it is condensed to liquid water (Fig. 4b, dark zone). As a result, a dryout zone is created near the heat source, and a condensation zone moves progressively away from the heat source. The remaining part of the evaporated water is lost through bulk head at the entrance of the heated drift.

High temperature gives rise to thermal expansion of the rock matrix, with associated TM-induced displacements and stresses (Fig. $4 \mathrm{~d}$ and e). Near the heat source, the horizontal compressive stress increases strongly, with a maximum increase at the drift wall and near the wing heaters (Fig. 4e). Such an increase in compressive stress reduces fracture apertures, leading to a decrease in fracture permeability. Away from the heat source, on the other hand, the horizontal stress decreases slightly (Fig. 4e, top). This decrease in horizontal stress unloads pre-existing vertical fractures that open to greater apertures, leading to an increase in fracture permeability in this area.

Fig. 4f presents the calculated THM-induced changes in air permeability in the fracture system. Changes in air permeability are caused by the combined effect of TH-induced changes in fracture moisture content, shown in Fig. 4b, and TM-induced changes in fracture aperture, shown in Fig. 4e. Near the heat source, permeability decreases mainly because of fracture closure, but is also affected by TH-induced wetting and drying. Away from the heat source, a zone of increased permeability has developed as a result of the opening of vertical fractures (Fig. $4 \mathrm{f}$, near borehole section 74:4). The modeling indicates that fracture closure/opening by changes in stress normal to fractures is the dominant mechanism for intrinsic permeability changes at the DST. This finding indicates that permeability changes caused by shear slip are small compared to those by normal stress.

\section{COMPARISON OF MODEL PREDICTIONS AND FIELD DATA}

This section compares simulated to measured THM responses in the DST test block. Simulated and measured rock temperatures are first compared in Section 6.1, since temperature change is the driving force behind the coupled THM processes at the DST. Sections 6.2 and 6.3 provide comparison of simulated and measured displacements, and fracture permeability, respectively.

\subsection{Rock Temperature}

Fig. 5 presents simulated and measured temperature profiles along a vertical borehole emanating from the crown of the heated drift, and Fig. 6 shows simulated and measured temperature evolution at the drift wall. The figures indicate an excellent agreement between simulated and measured temperature. Such an agreement could only be achieved by an explicit simulation of heat loss through the bulk head, located near the entrance of the heated drift. An extra grid element was added to the two-dimensional model to simulate out-of plane heat loss through the bulkhead. The properties of the bulkhead element, 
corresponding to a heat-loss coefficient of $0.4375 \mathrm{~W} /{ }^{\circ} \mathrm{K}$, were determined through model calibration against an early temperature measurement. Specifically, the calibration was made by matching a measured temperature of $150^{\circ} \mathrm{C}$ at the top drift of after 1 year of heating (Figure 5). Using this single calibration point, the model properly predicts the entire four-year temperature evolution and distribution.

\subsection{Rock Displacements}

Fig. 7 presents a comparison of the time evolution of rock-mass incremental displacements along extensometer boreholes (locations of extensometer boreholes are shown in Fig. 4d). Sensitivity analyses showed that displacement magnitudes are mainly dependent on the coefficient of thermal expansion, and to a lesser extent on the rock-mass deformation modulus. To display typical trends of the field data and their variability, the calculated values are compared to measurements that have been grouped into equivalent categories, based on their location relative to the heated drift.

The comparison shown in Fig. 7 is for six $60^{\circ}$ inclined boreholes (BH 147, 148, 154, 155, 178 and 179 in Fig. 4d) located in three borehole arrays at $y=41.1,21.0$, and $13.7 \mathrm{~m}$. All these arrays are located within the axial extension of the heated drift, with the one at $41.1 \mathrm{~m}$ being farthest out, located about $4.6 \mathrm{~m}$ from the end of the heated drift. The noticeable spread of the results may be attributed to the local rock-mass heterogeneities, such as fractures. With the exception of Anchor 1 and the early time results of Anchor 4, simulated displacements are within the range of the measured ones. The best agreement is obtained for Anchors 2 and 3, whereas the calculated displacement at Anchor 1 is a lower bound prediction. In Anchor 4, the early time displacements are slightly underpredicted, while the final average displacement at 50 months is well predicted. These results indicate that the intact-rock thermal expansion coefficient determined from core samples was appropriate for the in situ conditions at the DST.

In addition to a direct comparison of the evolution of measured and calculated individual values, we conducted a quantitative evaluation using statistical measures according to Wagner et al. [19]. One very useful statistical measure presented by Wagner et al. [19] is normalized-absolute-mean difference $(N A M D)$. The $N A M D$ for a specific time is described as:

$$
N A M D=\sum_{i=1}^{N}\left|\frac{V_{\text {sim }, i}-V_{\text {meas }, i}}{V_{\text {meas }, i}^{0}}\right| \cdot \frac{1}{N}
$$

where $\nu_{\text {meas }, i}$ in this case is measured displacement. NAMD provides a percentage of the absolute difference between measured $\left(V_{\text {meas, }}\right)$ and simulated $\left(V_{\text {sim }}, i\right)$ variables relative to the measured variable.

Fig. 8 presents the evolution of NAMD based on measured and calculated data for Anchors 1 to 4 along the various types of extensometer boreholes (inclined and vertical above and below drift). The NAMD is about $45 \%$ at 6 months, but gradually reduces to less than $25 \%$ after 24 months of heating. Thus, as a whole, the displacements at DST are predicted within $25 \%$ of measured values.

\subsection{Fracture Permeability}

The evolution of fracture permeability was compared at specific borehole locations where air-injection tests are conducted at regular time intervals of about three months. In this paper, three packed-off boreholes sections-denoted as 76:4, 74:4 and 76:1, located in a borehole array at $y=30.2 \mathrm{~m}$-are selected for a detailed comparison of simulated and measured evolution of fracture permeability (see locations of packed-off sections in Fig. 4f). These borehole sections are selected for comparison 
because they represent characteristic responses of fracture permeability at various locations around the heated drift: near the heat source (Section 76:4), far above the heat source (Section 74:4), and on far the side of the heat source (Section 76:1).

As discussed in Section 5, changes in air permeability are caused by the combined effect of THinduced changes in fracture moisture content (Fig. 4b) and TM-induced changes in fracture aper-ture (Fig. 4e). TH-induced changes in fracture moisture content cannot be directly measured, since the moisture in the fracture system is only a small fraction of the total moisture content for the entire fracture-matrix system. The drying in the matrix at the DST is monitored by geophysical methods that include ground penetrating radar, electric resistivity tomography, and neutron logs [11]. A comparison of those geophysical data with the simulated results indicates that the extent of the dryout zone is well captured in the numerical results.

TM-induced changes in fracture permeability are controlled by thermal stress and the adopted stressversus-permeability relationship. Sensitivity studies show that the stress-versus-permeability relationship is the most important parameter for predicting the evolution of fracture permeability. Obviously, if a more sensitive relationship between stress and permeability is adopted in the analysis, stronger changes in permeability will be predicted. It was also shown that the permeability changes in vertical and horizontal fractures can be very different in some areas around the drift. In general, the permeability changes more in vertical fractures than in horizontal, because vertical fractures are exposed to greater TM-induced stress changes.

Fig. 9 presents a comparison of measured and simulated fracture permeability (airflow permeability in the fracture system) for the three borehole sections. In this comparison, the calculated mean permeability is compared to the measured results. The mean permeability correction factor is represented by the geometric mean $F_{k}$ of permeability correction factors for directional permeability change factors according to Equation (4). In general, the simulated results are in agreement with the measured results.

At 76:4, the simulation correctly predicts a decrease in air permeability during the first two years. This decrease in air permeability is the combined effect of TM-induced fracture closure and TH-induced condensation in the fracture system. The modeling shows that a TM-induced decrease in intrinsic permeability occurs in both vertical and horizontal fractures. After about two years of heating, the measured air permeability appears to recover somewhat. Modeling shows that this partial recovery of air permeability can be explained by drying of the fracture system as the dryout zone expands beyond borehole section $76: 4$.

At 76:1, the model predicts a gradual reduction in air-permeability with time. Modeling showed that at this location, the intrinsic permeability of vertical fractures decreases, while the intrinsic permeability of horizontal fractures slightly increases. In the field, the net effect is a slight decrease in air permeability.

For Section 74:4, measured air permeability increases during the first two years and then gradually decreases. The modeling showed that this increase in permeability can be explained by a reduction in horizontal stress that tends to increase the aperture of vertical fractures. Section $74: 4$ is located so far from the heated drift that no significant changes in fracture moisture content occur at that location. Thus, measured changes in air permeability at $74: 4$ are likely to be a result of purely TM-induced fracture opening/closure. 


\section{CODE-TO-CODE COMARISON WITHIN THE DECOVALEX PROJECT}

As part of the international cooperative project DECOVALEX III (DEvelopment of COupled models and their VALidation against EXperiments, Project Phase III), four research teams used four different numerical models, including the one presented in this paper, to simulate and predict coupled THM processes at the DST [20]. The four research teams-Commissariat a l'Energie Atomique (CEA), France, Center for Nuclear Regulatory Analyses (CNWRA), USA, Lawrence Berkeley National Laboratory (LBNL), USA, and Technical University of Catalunya (UPC), Spain-all used continuum model approaches but with slightly different model conceptualizations. The analyses by UPC and LBNL included fully coupled THM modeling, whereas CEA and CNWRA conducted simplified TM analyses based on the measured temperature field. That is, the temperature field measured at the DST was imported at selected time intervals to their models and then thermally induced mechanical responses were calculated.

Other notable differences in the model approaches included different conceptualizations for mechanical analysis and for analysis of permeability changes. Most notably, CEA and CNWRA used elasto-plastic mechanical analysis, whereas LBNL and UPC used elastic analysis. The models by CNWRA and CEA included the concept of elasto-plastic ubiquitous joints for analysis of mechanical behavior of the rock mass. For the analysis of changes in permeability, CNWRA adopted an approach similar to that of LBNL (presented in this paper) with permeability changes calculated as a function of changes in normal stress across sets of fractures and having nonlinear relationships between normal stress and fracture permeability. However, instead of an exponential function (Equation (5)), CNWRA used the Bandis' [21] joint model to relate normal stress and changes in fracture aperture. In addition, CNWRA included changes in fracture aperture as a result of fracture shear displacements.

Fig. 10 presents comparison of the evolution of mechanical displacement and permeability changes. In general, the coupled THM responses were well captured by all teams and were in general agreement with the results presented in this paper. TM-induced rock deformations were generally well simulated using an elastic model, although some individual displacements appear to be better captured using an elasto-plastic model. More details about this code-intercomparison are provided in Rutqvist et al. [20].

The elasto-plastic analyses by CEA and CNWRA indicated that the highest potential for inelastic deformation in the form of fracture shear slip occurs near the drift wall, as well as in a zone of thermal stress decrease located more than $15 \mathrm{~m}$ above the heated drift. However, it appears that such shear slip is relatively small in magnitude and does not induce significant increases in fracture permeability. This is also indicated by the recent trends of permeability changes measured during the cooling phase of the DST. The measurements do not indicate any dramatic increases in permeability that could be a sign of shear slip dilation. Thus, fracture closure/opening caused by change in normal stress across fractures appear to be the dominant mechanism for TM-induced changes in intrinsic fracture permeability at the DST.

\section{CONCLUSIONS}

This paper presents analysis of coupled multiphase fluid flow, heat transfer, and mechanical deformation at the Yucca Mountain Drift Scale Test. The generally good agreement between simulated and measured temperature, displacement, and changes in air permeability shows that the numerical models and underlying conceptual models have captured the coupled THM processes at the DST. From the analyses and discussions presented in this paper, the following specific conclusions can be drawn:

- A continuum model approach is appropriate for simulating relevant coupled THM processes at the DST. 
- TM-induced rock deformations are generally well simulated using an elastic model, although some individual displacements appear to exhibit partly inelastic behavior.

- Away from the drift wall, fracture closure/opening caused by changes in normal stress across fractures is an important mechanism for TM-induced changes in intrinsic fracture permeability, whereas fracture shear dilation appears to be less significant.

- TM-induced changes in permeability at the DST, which are within one order of magnitude, are likely to be mostly reversible.

It will be very beneficial to follow the evolution of permeability changes during the cooling phase to confirm that TM-induced permeability changes are indeed partly or almost fully reversible.

\section{ACKNOWLEDGMENT}

Financial support was provided by The Director, Office of Civilian Radioactive Waste Management, U.S. Department of Energy, through Memorandum Purchase Order QA-B004220RB3X between Bechtel SAIC Company, LLC and the Ernest Orlando Lawrence Berkeley National Laboratory (Berkeley Lab), provided to Berkeley Lab through the U.S. Department of Energy Contract No. DE-AC03-76SF00098.

\section{REFERENCES}

1. Birkholzer JT, Tsang YW. 1997. Pretest Analysis of the Thermal-Hydrological Conditions of the ESF Drift Scale Test. Milestone SP9322M4. Berkeley, California: Lawrence Berkeley National Laboratory.

2. Birkholzer, J.T., and Y.W. Tsang. 2000. Modeling of thermal-hydrologic processes in a large-scale underground heater test in partially saturated tuff. Water Resources Research 36:1,431-1,447.

3. Mukhopadhyay, S., and Y.W. Tsang. 2003. Uncertainties in coupled thermal-hydrological processes associated with the Drift Scale Test at Yucca Mountain, Nevada. Journal of Contaminant Hydrology 62-63: 595-612.

4. Buscheck, T.A., R.J. Shaffer, and J.J. Nitao. 1997. Pretest thermal-hydrological analysis of the Drift-Scale Thermal Test at Yucca Mountain. ACC: MOL.19980507.0359, CRWMS M\&O, Las Vegas, Nevada.

5. Francis, N.D., S.R. Sobolik, C.K. Ho, R.R. Eaton, and D. Preece. 1997. Pre-experiment thermal-hydrologicalmechanical analyses for the ESF heated drift experiment. SLTR97-0002, CRWMS M\&O, Las Vegas, Nevada.

6. Blair, S.C. 2001. Coupled Thermal-Hydrologic-Mechanical Effects on Permeability Analysis and Models Report. ANL-NBS-HS-000037 REV 00. Bechtel SAIC Company, Las Vegas, Nevada.

7. Rutqvist, J., Y.S. Wu, C.F. Tsang, and G.S. Bodvarsson. 2002. A Modeling Approach for Analysis of Coupled Multiphase Fluid Flow, Heat Transfer, and Deformation in Fractured Porous Rock. Int. J. Rock mech. Min. Sci. 39: 429-442.

8. Rutqvist, J. and C.F. Tsang. 2003. TOUGH-FLAC: A numerical simulator for analysis of coupled thermalhydrologic-mechanical processes in fractured and porous geological media under multi-phase flow conditions. In Proceedings of the TOUGH symposium 2003, Lawrence Berkeley National Laboratory, Berkeley, May 12-14.

9. Pruess, K., C. Oldenburg, and G. Moridis. 1999. TOUGH2 User's Guide, Version 2.0, Report LBNL-43134, Lawrence Berkeley National Laboratory, Berkeley, California.

10. Itasca Consulting Group. 1997. FLAC 3D, Fast Lagrangian Analysis of Continua in 3 Dimensions. Version 2.0. Five volumes. Minneapolis, Minnesota: Itasca Consulting Group.

11. Wagner, R. 2002. Thermal Testing Measurements Report. ANL-NBS-HS-000041 REV 00. Las Vegas, Nevada: Bechtel SAIC Company.

12. Hinds, J.J., G.S. Bodvarsson, and G.H. Nieder-Westermann. 2003. Journal of Contaminant Hydrology 62-63: 111-132.

13. Wang, J.P., Cook, R. Trautz, S. Flexser, Q. Hu, R. Salve, D. Hudson, M. Conrad, Y. Tsang, K. Williams, W. Sol, and J. Turin. 2001. In-situ field testing of processes. ANL-NBS-HS-000005 REV01. Las Vegas, Nevada: Bechtel SAIC Company. 
14. Leverett, M.C. 1941. Capillary behavior in porous media. Trans AIME 142: 341-358.

15. van Genuchten, M.T. 1980. A closed-form equation for predicting the hydraulic conductivity of unsaturated soils. Soil Sci. Soc. Am. J. 44: 892-898.

16. Millard, A., and J. Rutqvist. 2004. Comparative analyses of predicted and measured displacements during the heating phase of the Yucca Mountain Drift Scale Test. In: Stephansson, O. et al. editors. Coupled T-H-M-C Processes in Geo-Systems: Fundamentals, Modelling, Experiments and Applications. Elsevier Geo-Engineering Book Series, Oxford. 187-192.

17. Rutqvist, J. and C.F. Tsang. 2003. Journal of Contaminant Hydrology 62-63: 637-652.

18. Rutqvist, J. 2004. Drift-Scale THM Model Report. MDL-NBS-HS-000017 rev 01. Bechtel SAIC, Las Vegas, NV.

19. Wagner, R.A., S. Ballard, S.C. Blair, and S., Mukhopadhyay. 2001. A methodology for validation of process models used to simulate thermal tests at Yucca Mountain. In Proceedings of the 38th U.S. Rock Mechanics Symposium, DC Rocks 2001, Washington, D.C., USA, 7-10 July 2001, eds. D. Elsworth et al, 631-636. Exton, Pennsylvania: A.A. Balkema.

20. Rutqvist, J., D. Barr, R. Datta, A. Gens, M. Millard, S. Olivella, C.F. Tsang , and Y. Tsang. 2005. Coupled thermal-hydrological-mechanical analysis of the Yucca Mountain Drift Scale Test - comparison of field results to predictions of four different models. Accepted for publication in Int. J. Rock mech. Min. Sci February 2005.

21. Bandis, S., A.C. Lumsden, and N.R. Barton. 1983. Fundamentals of rock joint deformation. Int J Rock Mech Min Sci \& Geomech Abstr 20:249-268. 
Table 1. Rock properties of the fractured welded tuff (Tptpmn unit) containing the DST test block

\begin{tabular}{|l|l|}
\hline \multicolumn{1}{|c|}{ Property } & Value \\
\hline \hline Matrix Hydraulic and Thermal Properties \\
\hline Permeability & $1.24 \mathrm{E}-17 \mathrm{~m}^{2}$ \\
\hline Porosity & 0.11 \\
\hline Van Genuchten, $\alpha_{\mathrm{m}}$ & $2.25 \mathrm{E}-6 \mathrm{~Pa}^{-1}$ \\
\hline Van Genuchten $\mathrm{m}_{\mathrm{m}}$ & 0.247 \\
\hline Residual saturation & 0.18 \\
\hline Rock grain density, $\rho$ & $2,530 \mathrm{~kg} / \mathrm{m} 3$ \\
\hline Rock grain specific heat & $953 \mathrm{~J} / \mathrm{kg} \mathrm{K})$ \\
\hline Dry thermal conductivity & $1.67 \mathrm{~W} / \mathrm{m} \mathrm{K}$ \\
\hline Wet thermal conductivity & $2.0 \mathrm{~W} / \mathrm{m} \mathrm{K}$ \\
\hline Fracture Hydrological and Hydro-Mechanical Properties \\
\hline Permeability, $\mathrm{k}$ & $1.00 \mathrm{E}-13 \mathrm{~m}^{2}$ \\
\hline Porosity & $0.263 \mathrm{E}-3$ \\
\hline Van Genuchten, $\alpha_{\mathrm{f}}$ & $9.73 \mathrm{E}-5 \mathrm{~Pa}$ \\
\hline Van Genuchten, $\mathrm{m}_{\mathrm{f}}(-)$ & 0.492 \\
\hline Residual saturation & 0.01 \\
\hline Fracture frequency & $4.32 \mathrm{~m}^{-1}$ \\
\hline$b_{\max }$ for Equation $(5)$ & $150 \mu \mathrm{m}$ \\
\hline Exponent $d$ for Equation $(5)$ & $0.6 \mathrm{MPa}{ }^{-1}$ \\
\hline Rock Mass Mechanical Properties \\
\hline Young's Modulus & $14.77 \mathrm{GPa}$ \\
\hline Poisson's ratio & 0.21 \\
\hline Thermal Expan. Coeff. & $5+0.0583 \times \mathrm{T} 10^{-6} /{ }^{\circ} \mathrm{C}$ \\
\hline
\end{tabular}

Table 2. Initial conditions

\begin{tabular}{|l|l|}
\hline Parameter & $\begin{array}{l}\text { Approximate value } \\
\text { at the level of DST }\end{array}$ \\
\hline \hline Vertical stress, $\sigma_{z i}$ & $\approx 5.7 \mathrm{MPa}$ \\
\hline Min horizontal stress, $\sigma_{y i}$ & $\approx 2.9 \mathrm{MPa}$ \\
\hline Max horizontal stress, $\sigma_{x i}$ & $\approx 3.4 \mathrm{MPa}$ \\
\hline Initial temperature, $\mathrm{T}_{1}$ & $\approx 25^{\circ} \mathrm{C}$ \\
\hline Initial Fracture saturation & $\approx 9 \%$ \\
\hline Initial matrix saturation & $\approx 90 \%$ \\
\hline Initial gas pressure & $\approx 0.9 \mathrm{bar}$ \\
\hline
\end{tabular}

${ }^{1}$ Approximate values of the depth-dependent parameters at the drift level. 


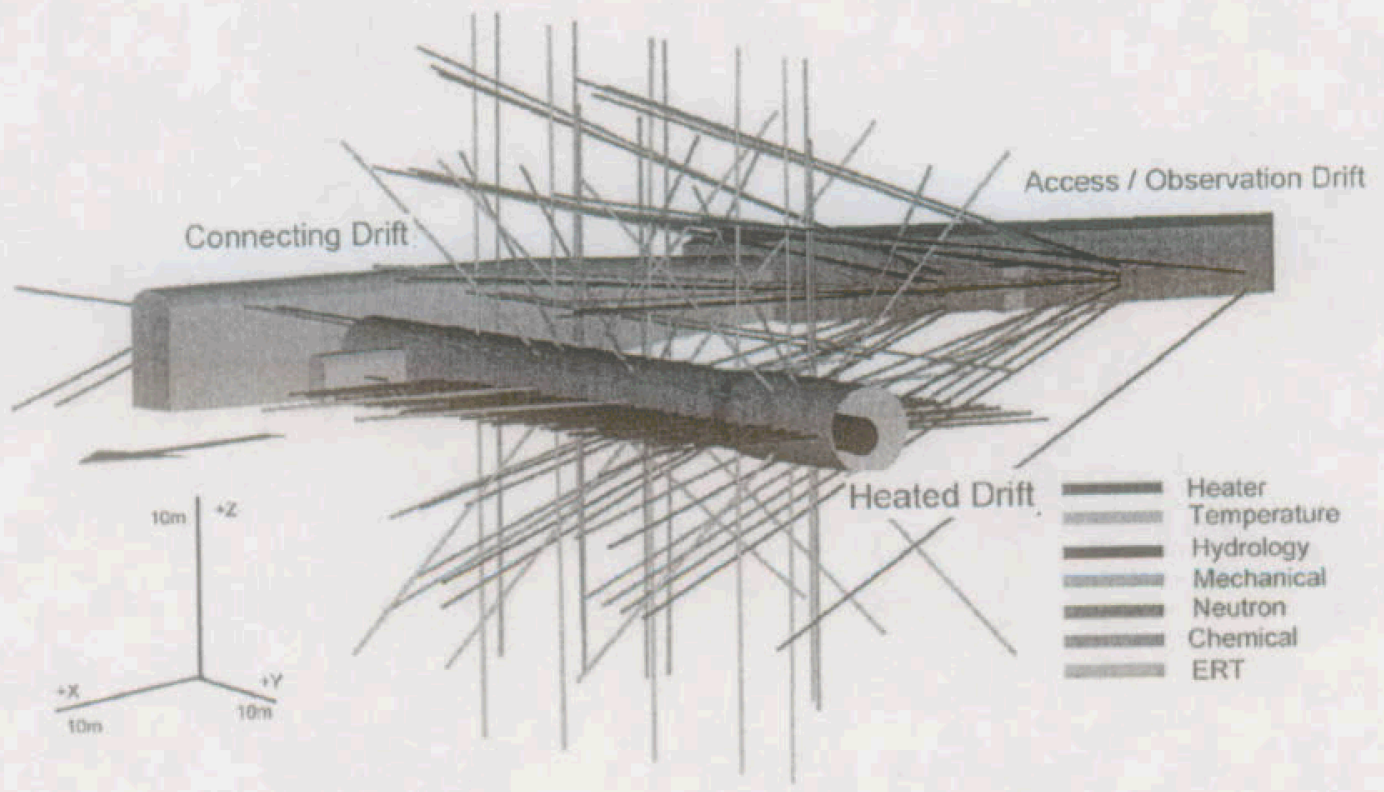

Fig. 1. Three-dimensional view of the Yucca Mountain Drift Scale Test. The color-coded lines indicate boreholes for various measurements of thermally driven THMC responses. 


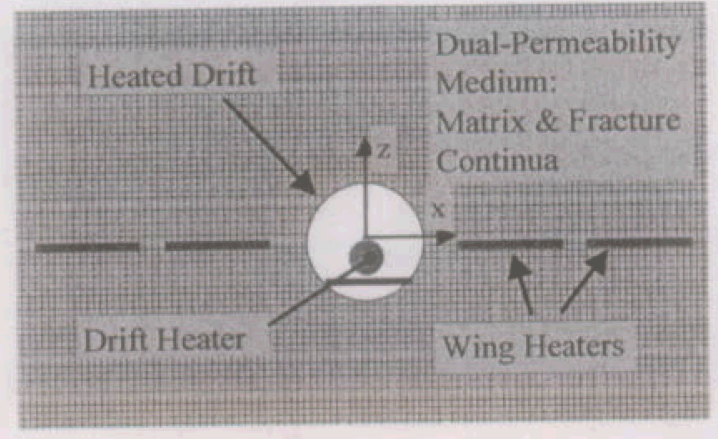

(a)

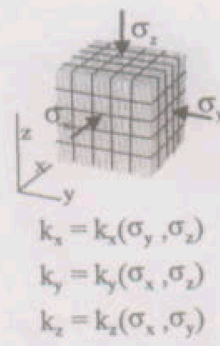

(b)

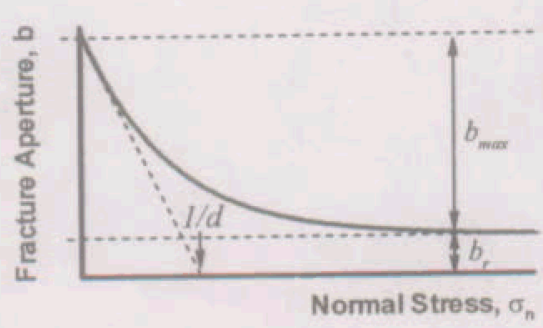

(c)

Fig. 2. TOUGH-FLAC simulation of the DST: (a) schematics of two-dimensional model geometry and dual-permeability model; (b) conceptual model for stress-permeability coupling; (c) normal stress versus aperture relationship for fractures. 


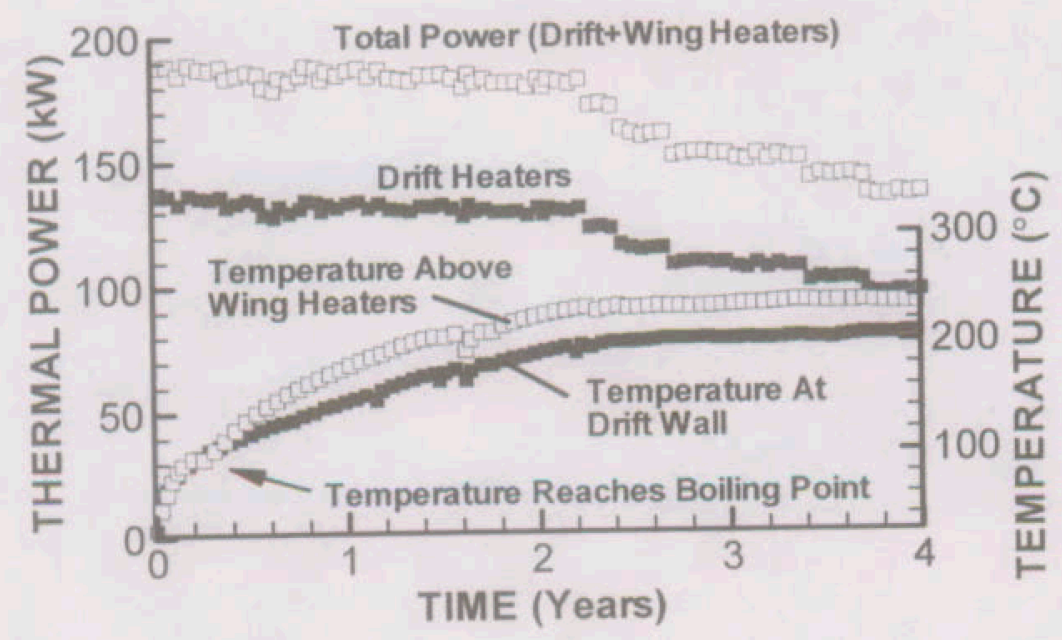

Fig. 3. Thermal power and measured temperature at the drift wall and at a monitoring point located above the wing heater at a horizontal distance of $10 \mathrm{~m}$ from the center of the drift. 


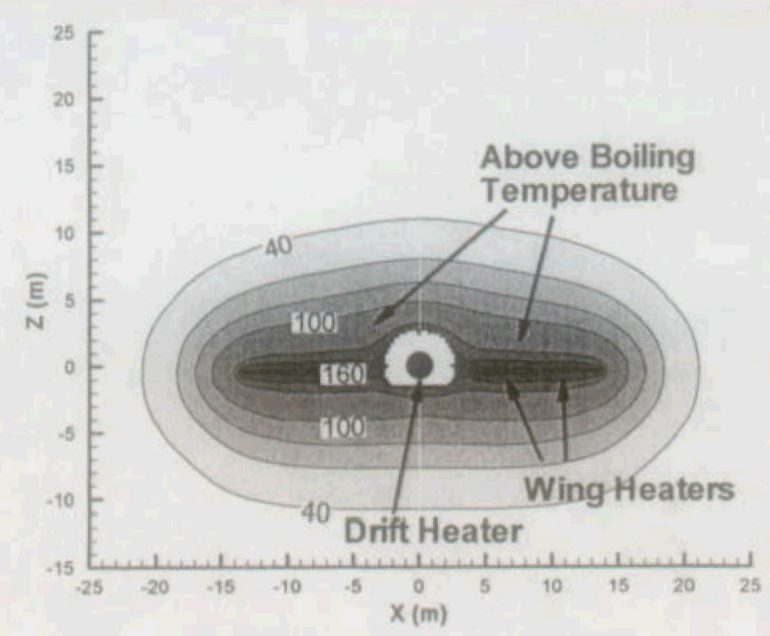

(a) Temperature

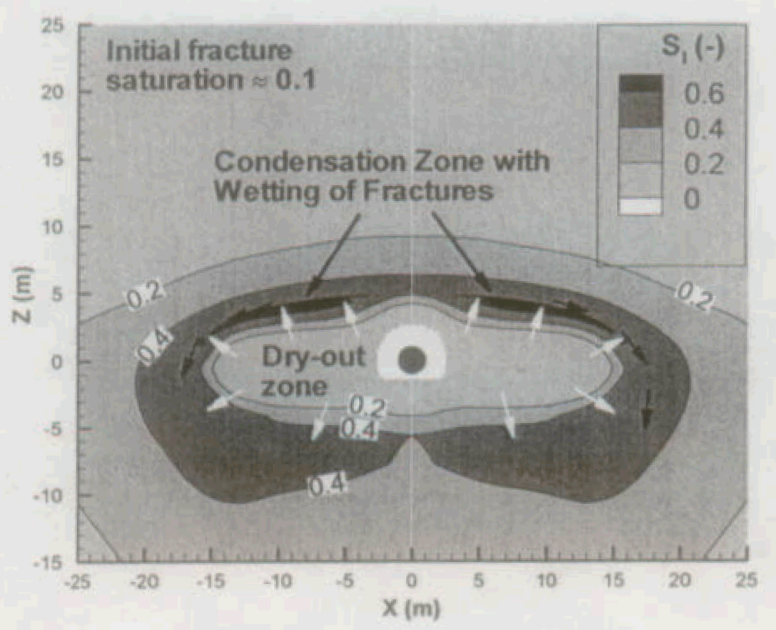

(b) Fracture saturation

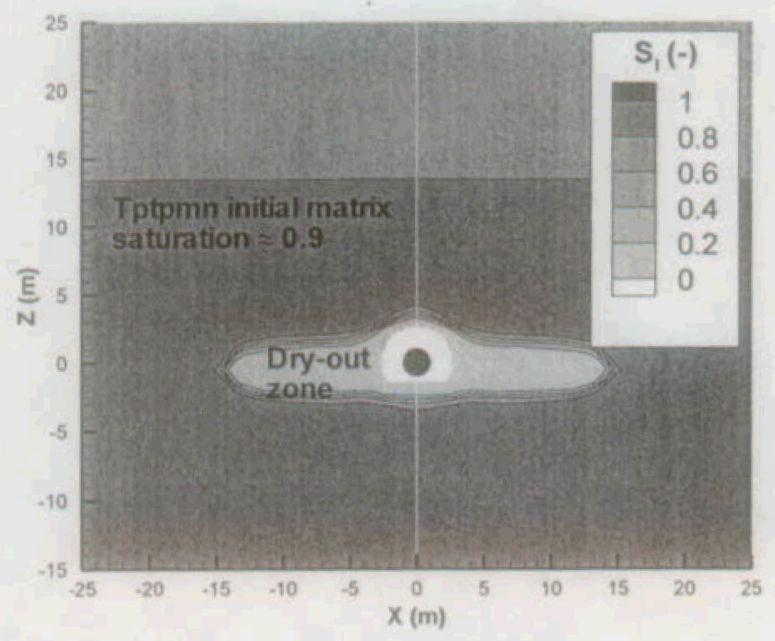

(c) Matrix saturation

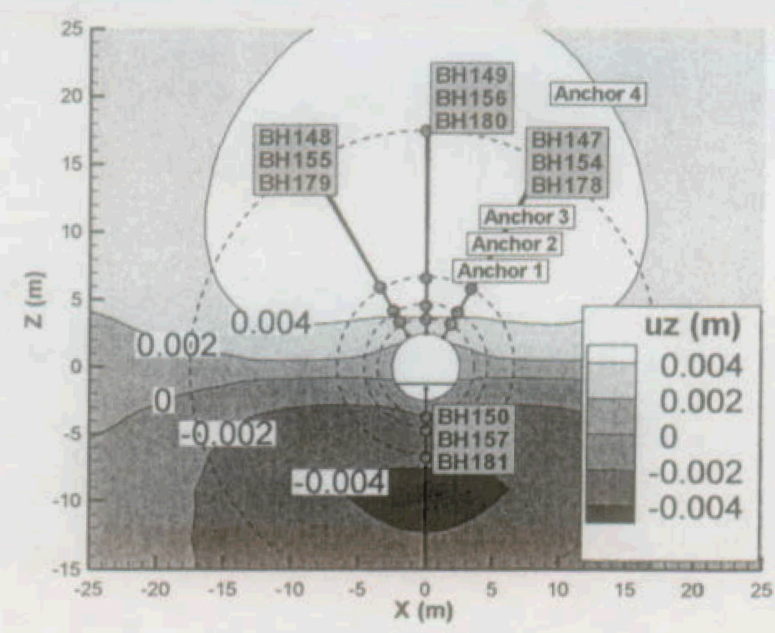

(d) Displacement

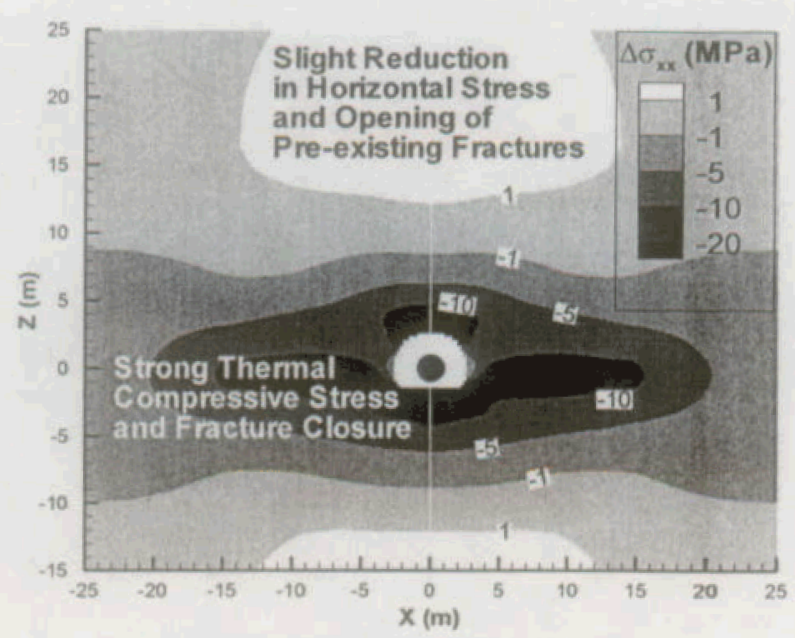

(e) Thermal stress

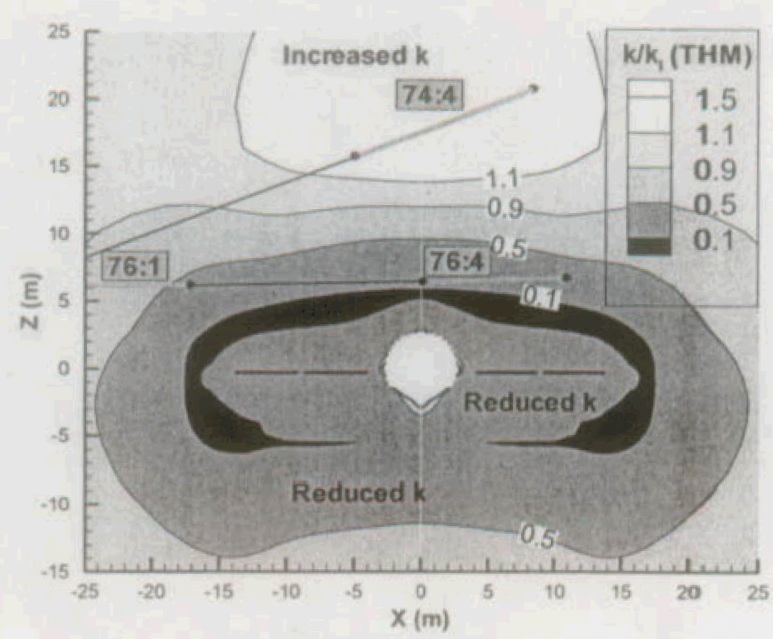

(f) Permeability correction factor

Fig. 4. Calculated distribution of (a) temperature, (b) liquid saturation in fractures, (c) liquid saturation in rock matrix, (d) thermally induced horizontal stress, (e) thermally induced vertical displacement, (f) thermally induced vertical displacement and THM-induced changes in fracture permeability after one year of heating. 


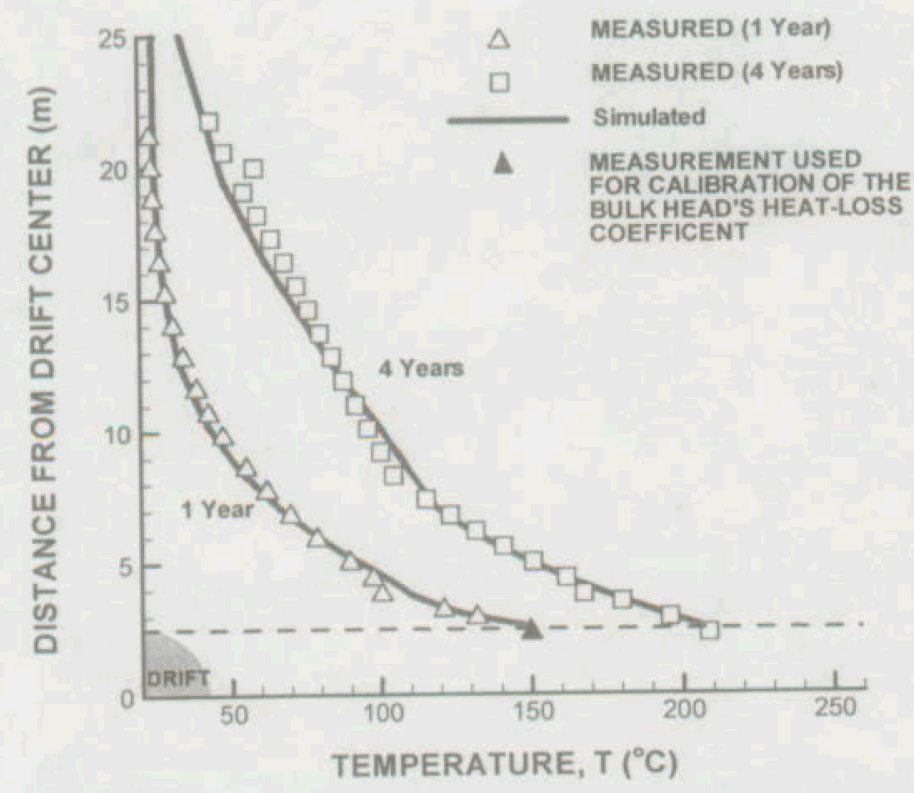

Fig. 5. Measured and simulated temperature profile along borehole 158 extending upward from the crown of the drift. 


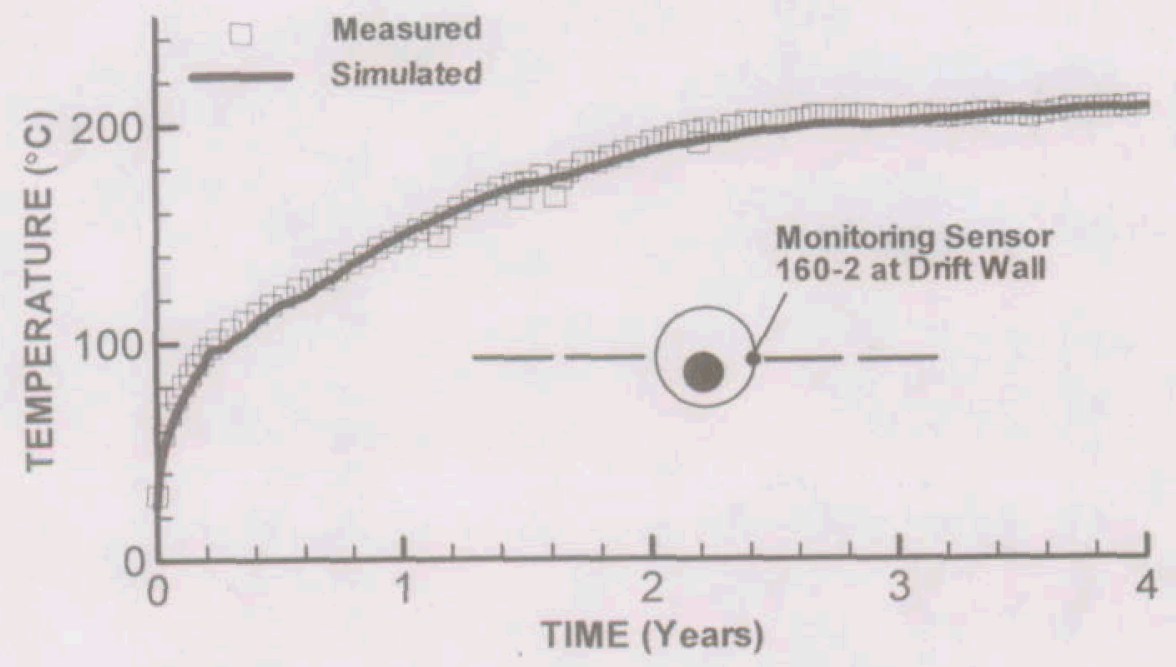

Fig. 6. Comparison of evolution of simulated and measured temperature at the drift wall. 


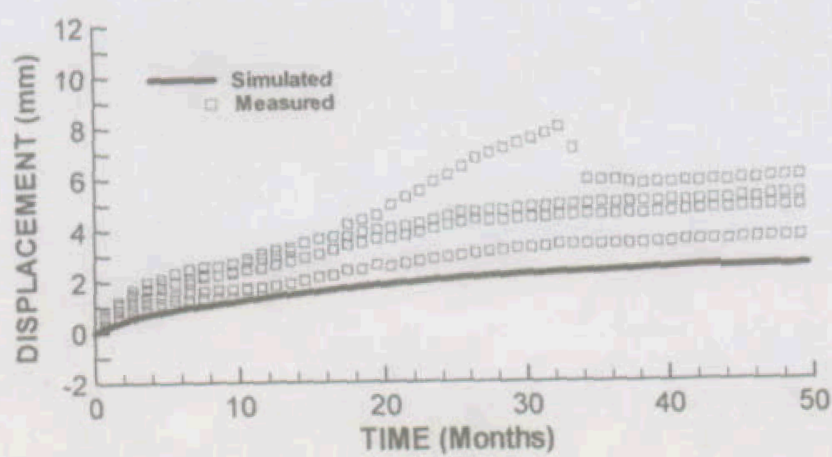

(a) Anchor 1

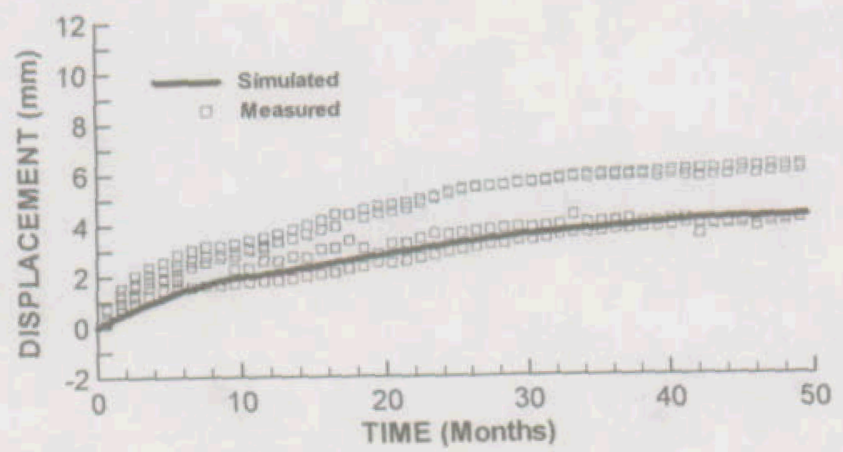

(b) Anchor 2

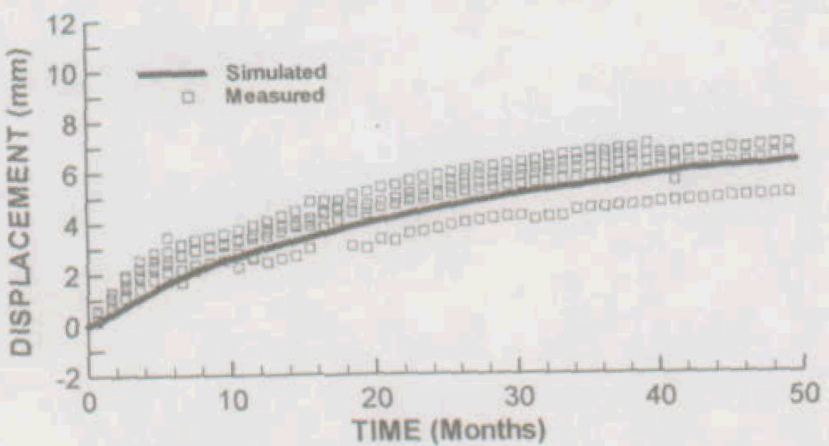

(c) Anchor 3

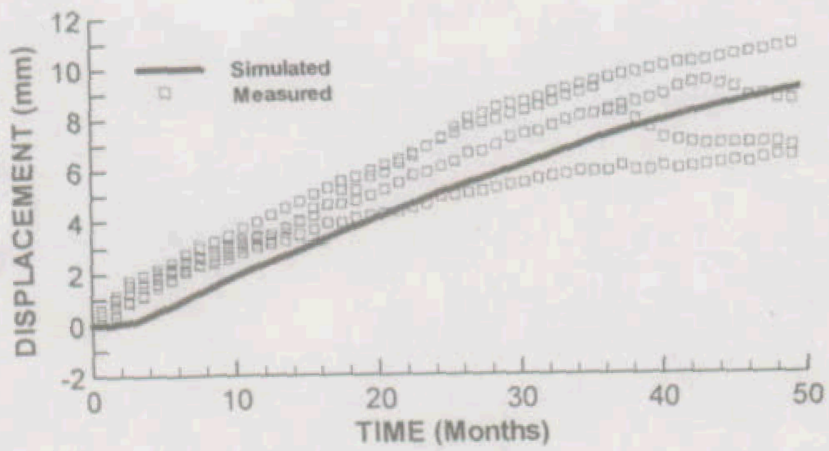

(d) Anchor 4

Fig. 7. Measured and simulated displacements for $60^{\circ}$ inclined boreholes 


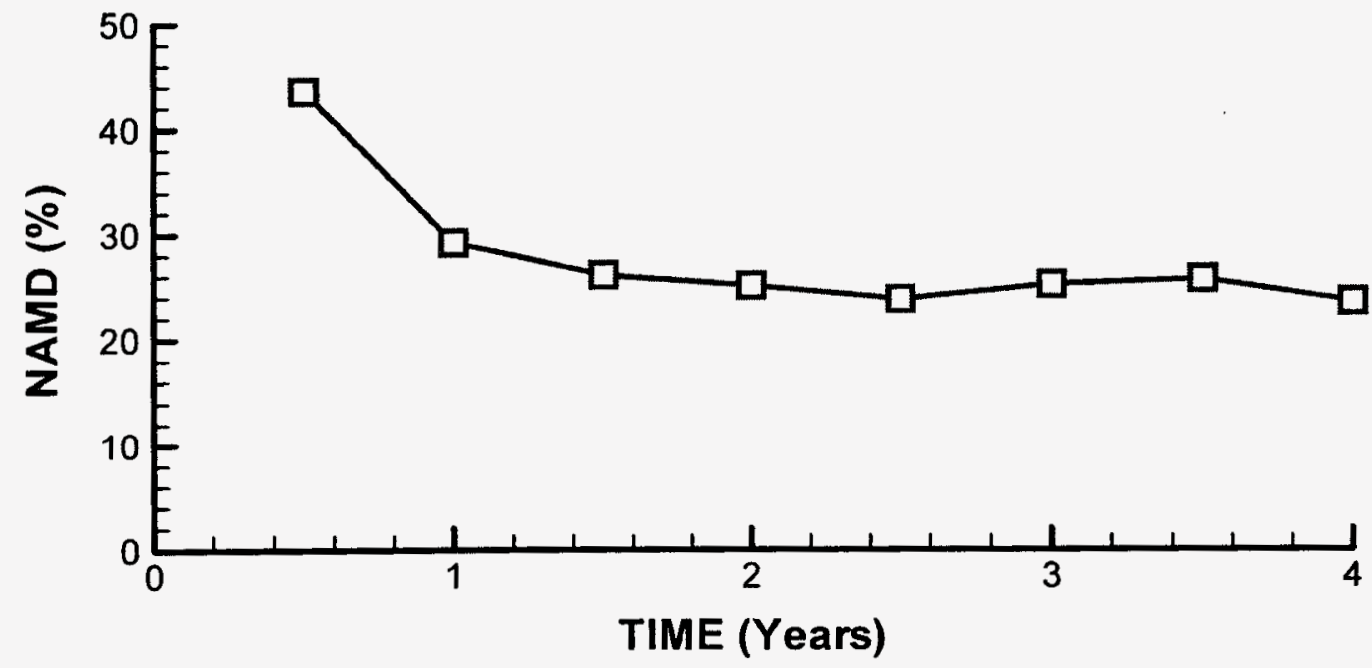

Fig. 8. Normalized-absolute-mean difference (NAMD) as a statistical measure for displacement comparative analysis [18]. 


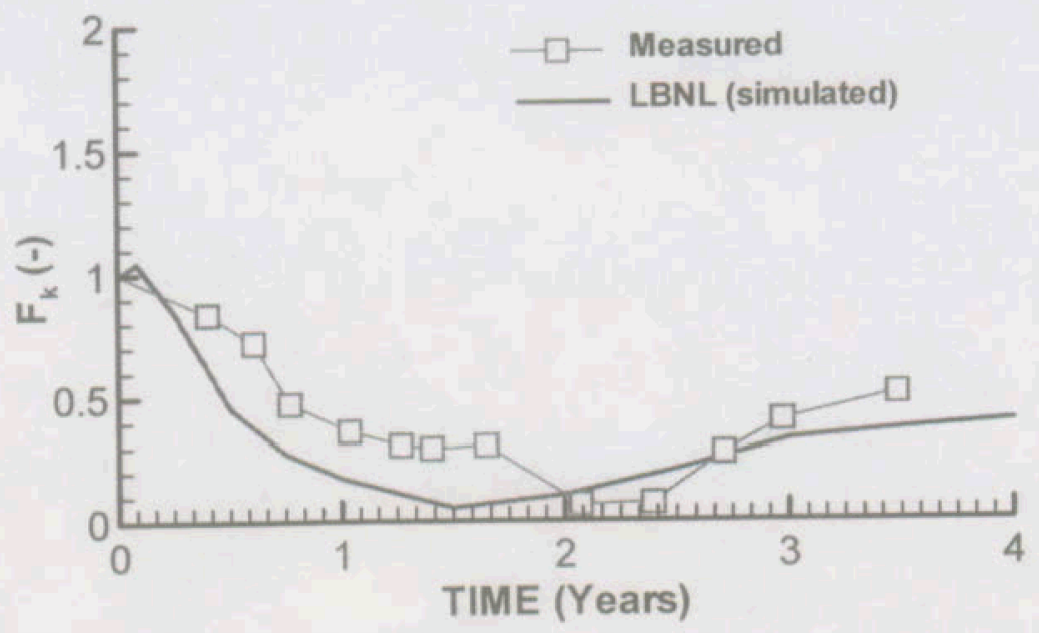

(a) Section 76:4

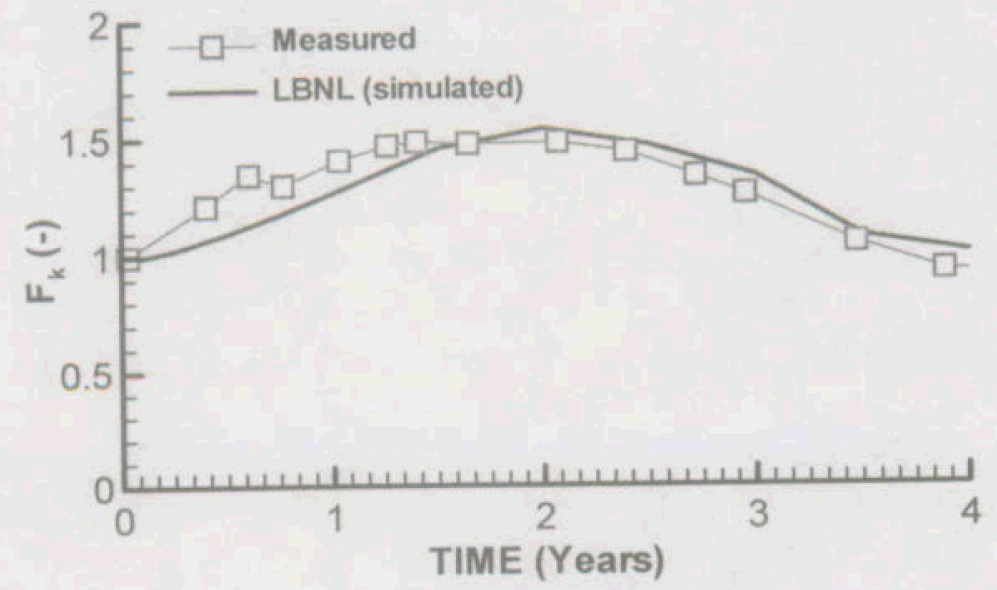

(b) Section 74:4

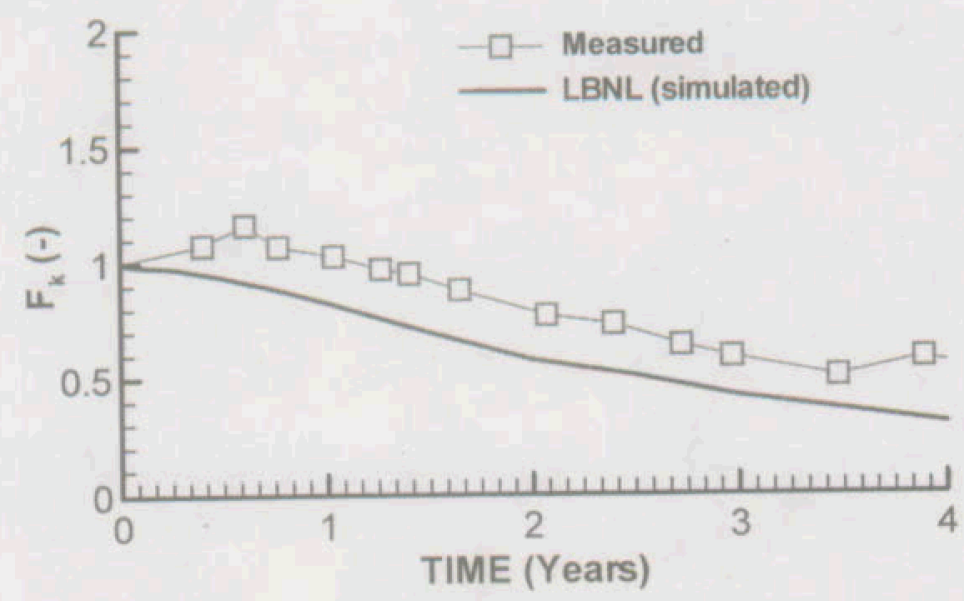

(c) Section 76:1

Fig. 9. Measured and simulated evolution of permeability correction factor $\left(F_{k}=k / k_{i}\right)$ for three different borehole sections. 


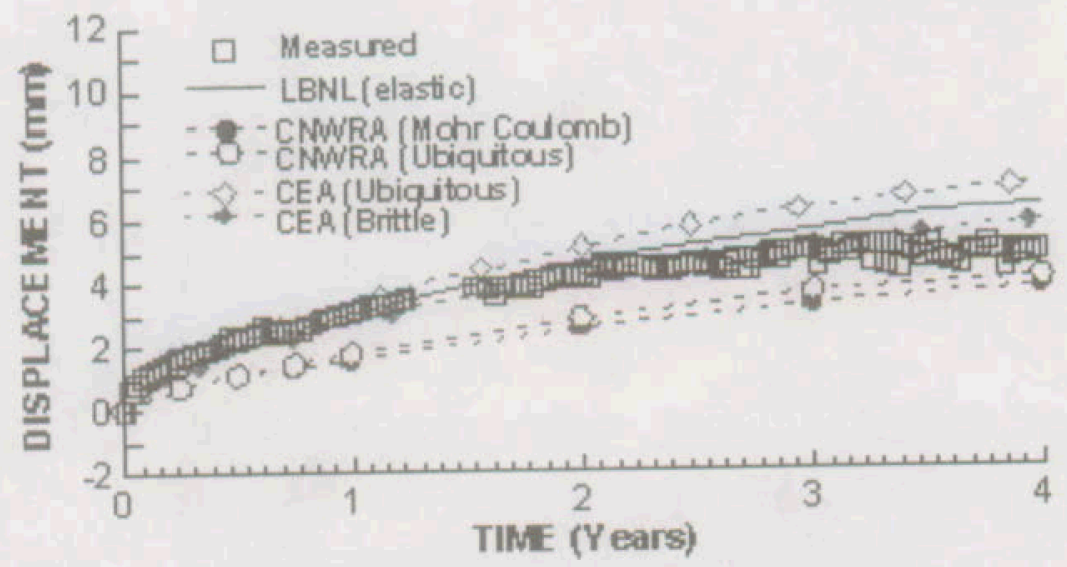

(a) Displacement at borehole 155 anchor 3.

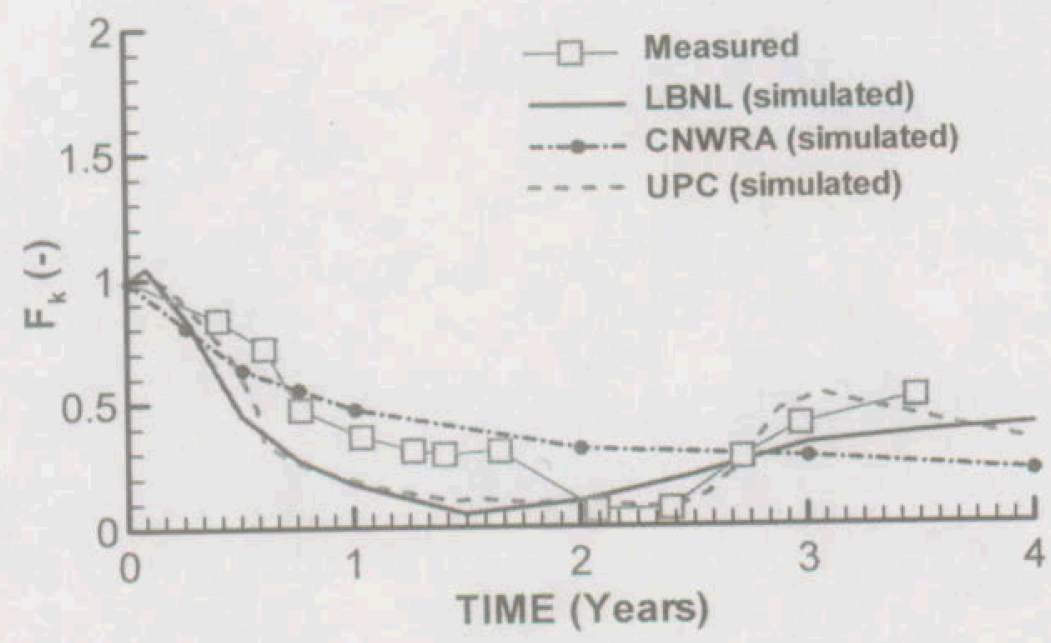

(b) Permeability correction factor in section $76: 4$

Fig. 10. Comparison of measured and simulated displacements by various research teams within the international DECOVALEX project [20]. 